\title{
BMJ Open Individual, maternal and household risk factors for anaemia among young children in sub-Saharan Africa: a cross- sectional study
}

\author{
Peter P Moschovis, ${ }^{1}$ Matthew O Wiens, ${ }^{2}$ Lauren Arlington, ${ }^{1}$ Olga Antsygina, ${ }^{3}$ \\ Douglas Hayden, ${ }^{1}$ Walter Dzik, ${ }^{1}$ Julius P Kiwanuka, ${ }^{4}$ David C Christiani, ${ }^{1,5}$ \\ Patricia L Hibberd ${ }^{6}$
}

To cite: Moschovis PP, Wiens M0, Arlington L, et al. Individual, maternal and household risk factors for anaemia among young children in sub-Saharan Africa: a crosssectional study. BMJ Open 2018;8:e019654. doi:10.1136/ bmjopen-2017-019654

- Prepublication history and additional material for this paper are available online. To view these files, please visit the journal online (http://dx.doi. org/10.1136/bmjopen-2017019654).

Received 18 September 2017 Revised 31 January 2018 Accepted 10 April 2018

\section{Check for updates}

${ }^{1}$ Massachusetts General Hospital, Boston, Massachusetts USA

${ }^{2}$ University of British Columbia, Vancouver, British Columbia, Canada

${ }^{3}$ Scientific Research Institute of Healthcare Organization and Medical Management, Moscow, Russia

${ }^{4}$ Mbarara University of Science and Technology, Mbarara,

Uganda

${ }^{5}$ Harvard T. H. Chan School of Public Health, Boston,

Massachusetts, USA

${ }^{6}$ Boston University School of Public Health, Boston, Massachusetts, USA

Correspondence to Dr Peter P Moschovis; pmoschovis@mgh.harvard.edu

\section{ABSTRACT}

Objective Anaemia affects the majority of children in subSaharan Africa (SSA). Previous studies of risk factors for anaemia have been limited by sample size, geography and the association of many risk factors with poverty. In order to measure the relative impact of individual, maternal and household risk factors for anaemia in young children, we analysed data from all SSA countries that performed haemoglobin $(\mathrm{Hb})$ testing in the Demographic and Health Surveys.

Design and setting This cross-sectional study pooled household-level data from the most recent Demographic and Health Surveys conducted in 27 SSA between 2008 and 2014.

Participants 96804 children age 6-59 months.

Results The prevalence of childhood anaemia (defined as $\mathrm{Hb}<11 \mathrm{~g} / \mathrm{dL}$ ) across the region was $59.9 \%$, ranging from $23.7 \%$ in Rwanda to $87.9 \%$ in Burkina Faso. In multivariable regression models, older age, female sex, greater wealth, fewer household members, greater heightfor-age, older maternal age, higher maternal body mass index, current maternal pregnancy and higher maternal $\mathrm{Hb}$, and absence of recent fever were associated with higher $\mathrm{Hb}$ in tested children. Demographic, socioeconomic factors, family structure, water/sanitation, growth, maternal health and recent illnesses were significantly associated with the presence of childhood anaemia. These risk factor groups explain a significant fraction of anaemia (ranging from 1.0\% to $16.7 \%$ ) at the population level. Conclusions The findings from our analysis of risk factors for anaemia in SSA underscore the importance of family and socioeconomic context in childhood anaemia. These data highlight the need for integrated programmes that address the multifactorial nature of childhood anaemia.

\section{INTRODUCTION}

Anaemia affects $43 \%$ of children under age 5 worldwide, with an even higher prevalence in sub-Saharan African (SSA) countries. ${ }^{1}$ Despite implementation of control programmes including iron supplementation, deworming and insecticide-treated bednet distribution, anaemia remains a major global concern
Strengths and limitations of this study

- This analysis of survey data across an entire region provides a unique perspective on the epidemiology of anaemia in a high-risk population.

- The size of this dataset provided sufficient power to estimate the effect size of individual risk factors in a multivariable model, adjusting for many known confounders.

- The data based on self-reporting are limited by recall and misclassification biases, and only children living at the time of the survey were included.

- The cross-sectional nature of these survey data limits our ability to assess temporal or causal relationships.

in child health, especially in SSA. ${ }^{2}$ While it may be difficult to separate the effects of anaemia (low haemoglobin $(\mathrm{Hb})$ ) from those of its underlying biological mechanisms (eg, nutritional deficiencies, chronic infections, haemoglobinopathies), anaemia has been independently associated with overall increased mortality in young children, ${ }^{3}$ with lower cognitive performance, ${ }^{45}$ and in severe cases, lower aerobic exercise capacity and heart failure. ${ }^{67}$ The higher oxygen demands of the paediatric brain make it particularly susceptible to the effects of severe anaemia. ${ }^{89}$

Several regional or national studies have examined the role of demographic, social, environmental and geographic determinants of anaemia. These studies have identified younger age,${ }^{10-14}$ male sex,${ }^{101113}$ maternal age and education, ${ }^{10}{ }^{15}$ maternal anaemia, ${ }^{16-18}$ malnutrition (especially stunting), ${ }^{10}{ }^{13}{ }^{19-21}$ insufficient meals per day, ${ }^{22}$ parasitic infection $^{21}$ and recent diarrhoea, ${ }^{12}{ }^{23}$ fever $^{23}$ and absence of deworming ${ }^{14}{ }^{24}$ as significant risk factors for childhood anaemia. An analysis of the National Family and Health Survey (the 
local implementation of the Demographic and Health Surveys (DHS)) in India found that high-polluting cooking fuel, family structure, building type and toilet facilities were associated with anaemia, ${ }^{14}$ but a study in Cape Verde evaluating the impact of 'household conditions' (water/sanitation, cooking facilities, appliances, building materials) did not find a significant association with anaemia, though the power to detect an association may have been limited by the study's sample size. ${ }^{12} \mathrm{~A}$ 2009 country-level analysis of DHS data level found that per capita Gross National Income predicts rates of severe anaemia. ${ }^{25}$

Because of the complex interconnectedness of many of these risk factors, especially in relation to poverty, it is important to evaluate potential risk factors for anaemia in a multivariable model. Each of the aforementioned studies has evaluated a subset of risk factors separately, but to our knowledge, there has been no continent-wide analysis that integrates the wide array of household and individual risk factors for anaemia among children in SSA. Building on these prior studies, we analysed data from all SSA countries that performed $\mathrm{Hb}$ testing during the most recent administration of the DHS. The objective of this study is to offer a population-level analysis of anaemia in young children in SSA by measuring the relative impact of individual, maternal and household risk factors for anaemia across the region.

\section{SUBJECTS AND METHODS}

\section{Population and data source}

The DHS provides a unique perspective on child health in low-and-middle-income countries. These are nationally representative, probability-weighted, community-based household surveys, funded by the U.S. Agency for International Development with support from donors and host countries. The DHS programme enables countries to measure a wide variety of demographic and health indicators, including fertility, child mortality, nutrition, growth and access to healthcare. Since 1984, household surveys have been supported by DHS in $>90$ countries. ${ }^{26} 27$ Participating households are selected using a stratified two-stage cluster design. First, enumeration areas are selected using stratified random sampling from national census regions (strata); within these areas, households are randomly selected for survey administration. The household questionnaire is administered to women and men of reproductive age (typically age 15-49 years); the women's questionnaire includes questions about child health.

We included data from children age 6-59 months in the 27 SSA countries participating in the DHS that performed anaemia testing (see figures 1 and 2). We analysed the Children's Recode using data from the most recent surveys available (2008-2014). In most cases, we used data from DHS-VI; for Ghana we used data from DHS-VII; for Sao Tome and Principe and Swaziland we used data from DHS-V. Madagascar was excluded from the analysis because of missing data on children's weight.

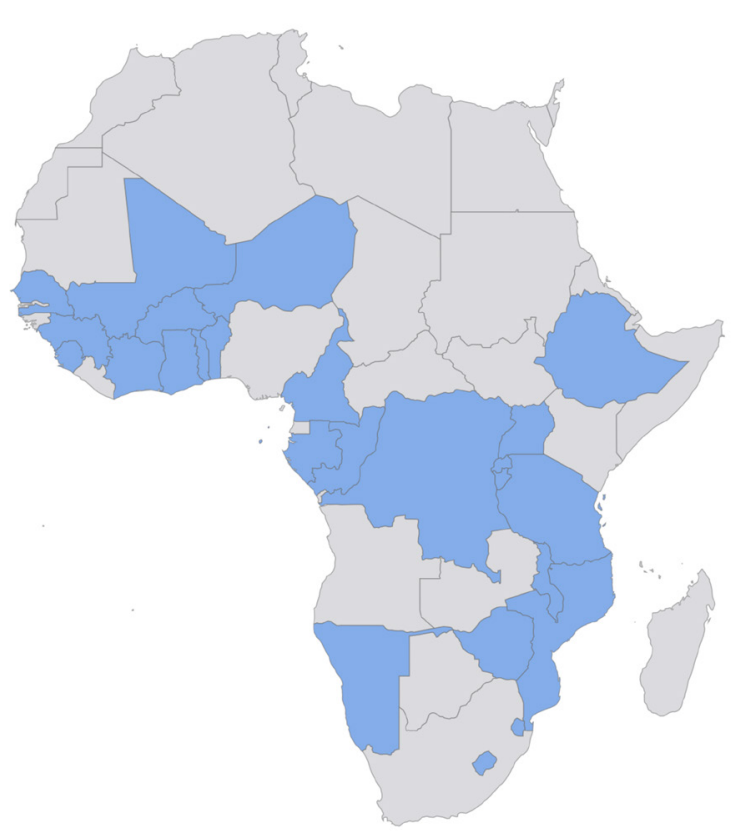

Figure 1 Map of 27 sub-Saharan African countries included in analysis.

Responses were recoded to harmonise questionnaires that varied between countries and survey phases.

\section{Survey procedures and anaemia testing}

A questionnaire was administered to an eligible adult respondent, and anthropometry and $\mathrm{Hb}$ testing were conducted on children age 6-59 months and their mothers during the study visit. In all countries but Tanzania and Zimbabwe, where universal testing was performed, only a subset of households were selected for anaemia testing. Capillary $\mathrm{Hb}$ testing was performed with the HemoCue

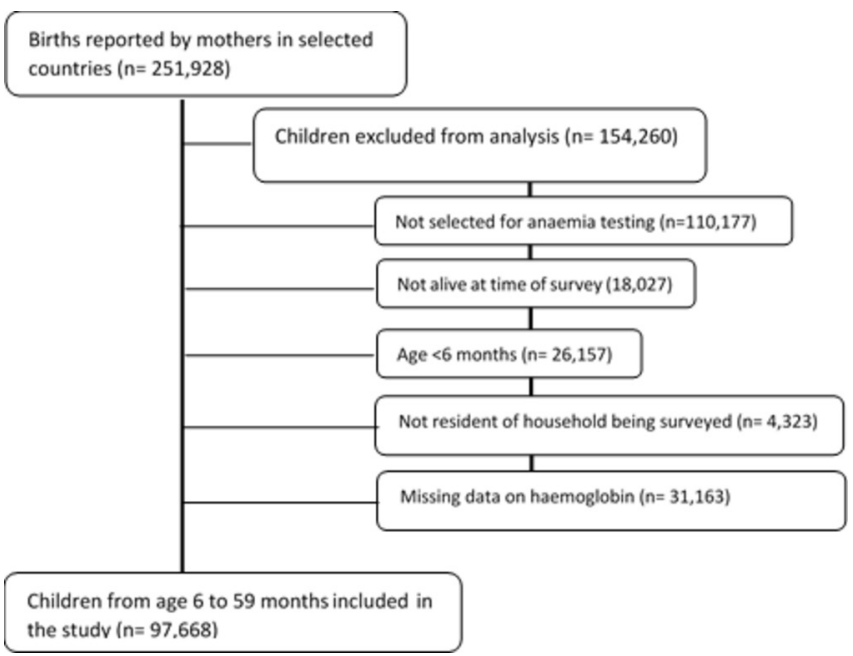

Figure 2 Selection of study population. Note that some children were excluded for multiple reasons. 
Photometer, which is commonly used in screening for anaemia in low-resource settings. ${ }^{28}$ Children found to have severe anaemia were referred to local health facilities for treatment. ${ }^{29}$ Anaemia severity was classified according to the WHO's 'Haemoglobin concentrations for the diagnosis of anaemia and assessment of severity' as mild, moderate or severe based on blood $\mathrm{Hb},{ }^{30}$ and the relevant thresholds for anaemia severity were used for children, pregnant and non-pregnant women.

\section{Analytic approach}

We performed bivariate analyses and multivariable logistic and linear regression using survey procedures in Stata V.14. The svy procedures are a set of commands that account for sampling weights, clustering and stratification in complex survey data. For the purposes of this analysis, the levels of clustering that were considered in the variance estimates include country-based primary sampling unit, the household and the mother. The original individual sample weight from each dataset was used for each respondent. We selected variables from the DHS questionnaire based on potential association with risk of anaemia. We grouped risk factors as follows: demographic (child's age, sex), environmental (urban vs rural location, altitude, floor type in home, biomass fuel used for cooking), socioeconomic (wealth index (a standardised variable constructed by the DHS using permanent income indicators), ${ }^{31}$ maternal years of education, maternal literacy), family structure (number of household members, number of children, birth order, multiple births), water/sanitation (use of shared toilet facilities, unimproved toilets, unimproved water source, water source located off premises, unsafe stool disposal), nutrition and growth (heightfor-age $\mathrm{Z}$ score (HAZ), weight-for-age $\mathrm{Z}$ score (WAZ), weight-for-height $\mathrm{Z}$ score (WHZ), ever breast fed, meat consumption in the last 24 hours, consumption of highiron foods in the last 24 hours), maternal health (maternal age, height, weight, body mass index (BMI), Hb, current pregnancy, iron supplementation and deworming during pregnancy), recent illnesses (diarrhoea or fever in the past two weeks) and prophylactic measures (iron supplementation in the last week, deworming in the last six months, bednet usage last night).

\section{Variable definitions}

Following WHO guidelines, ${ }^{32}$ unimproved toilet facilities were defined as pit latrines without slabs or platforms, open pit, hanging latrines, bucket latrines or open defecation. Improved toilet facilities were defined as a flush toilet, ventilated improved pit latrine, pit latrine with a slab, composting toilet or Ecosan. Unsafe stool disposal was defined as a child's stool put or rinsed into drain or ditch, thrown into garbage, rinsed away or left in the open/not disposed of. Safe stool disposal was defined as a child's use of toilet or latrine, faecal matter put or rinsed into a toilet or latrine, faecal matter buried, use of disposable diapers or use of washable diapers. An improved water source was defined as the main source of drinking water of piped connection to water supply, private and public tap, borehole, protected/dug well, protected spring, rainwater or bottled water. All other sources were considered unimproved. Unimproved floor was defined as natural, earth, sand, dung or rudimentary floor in the home. Cooking fuels were classified as biomass/high-polluting (kerosene, coal, lignite, charcoal, wood, straw, shrub, grass, agricultural crop, animal dung, gasoline or other) or non-biomass/low-polluting (electricity, liquefied petroleum gas, natural gas or biogas). Having a highiron diet was defined as reporting one or more iron-rich foods in the past 24 hours, which includes infant formula, grains, meat or meat organs, leafy greens or other foods such as beans, peas, lentils and nuts. For maternal iron supplementation and maternal deworming during pregnancy, in children $>12$ months these variables were coded as 'not applicable'. While the DHS reports altitude-adjusted $\mathrm{Hb}$ values in its publicly available data, in order to allow estimation of the effect of altitude on $\mathrm{Hb}$ and because altitude was missing for $26.4 \%$ of the sample, our analyses used unadjusted $\mathrm{Hb}$ rather than altitude-adjusted $\mathrm{Hb}$ values.

A pairwise correlation was performed to determine the relationship between highly correlated variables. For this test, anything $>0.6$ was considered to be highly correlated. When choosing among highly correlated variables (eg, HAZ/WAZ/WHZ, maternal height/weight/BMI, number of household members/number of children, maternal iron supplementation/deworming during pregnancy), we selected the single variable that when added to the multivariable model improved the predictive value of the model most (greatest contribution to overall $R^{2}$ ). For the bivariate analysis, we determined significance using ordered logistic regression to reflect natural ordering in multilevel categorical variables. All multivariable models included country as a fixed effect.

\section{Missing data}

Because several predictor variables were missing in a substantial number of respondents (online Supplementary table A1), we constructed three multivariable linear regression models: (1) model 1, which included only variables present in $>90 \%$ of respondents; (2) model 2 , which included variables present in $>80 \%$ of respondents; and (3) model 3 , which included all potentially relevant variables. For the anthropometric variables, which were missing in $4.7 \%$ of respondents, we performed a sensitivity analysis in which we assigned extreme values to all missing cases $(\mathrm{HAZ}=+2$ or $\mathrm{HAZ}=-2)$.

\section{Population-attributable fraction}

With the risk factors used in model 1 , we constructed a multivariable logistic regression model to measure the association between the risk factors of interest and anaemia (as a dichotomous variable). To facilitate ease of interpretation, we converted continuous variables to categorical and standardised the reference group to ensure ORs were $>1$. We used the OR estimates to calculate 
population-attributable fraction $(\mathrm{PAF})$, the proportion of anaemia in children age 6-59 months that can be attributed to the risk factor in question. This was calculated using the punaf command in Stata, ${ }^{33}$ which measures the proportion of respondents who would no longer be anaemic if the risk factor in question were removed (or at its lowest risk category) and all other risk factors held constant. Respondents provided informed consent prior to participation and provided separate consent for blood testing.

\section{RESULTS}

Data on a total of 251928 children across 27 countries were reviewed, of which 97668 had valid data for analysis (residents of households selected for anaemia testing, alive at the time of the survey and age $\geq 6$ months; see figure 2). The mean age of children in the survey was 31.5 months (SD 15.5), with $49.6 \%$ of the children female. The mean $\mathrm{Hb}$ among tested children was $10.4 \mathrm{~g} / \mathrm{dL}$ (SD $1.8) ; 23.6 \%$ of children were found to have mild anaemia (Hb $10.0-10.9 \mathrm{~g} / \mathrm{dL}$ ), $34.4 \%$ of children had moderate anaemia $(\mathrm{Hb} 7.0-9.9 \mathrm{~g} / \mathrm{dL})$ and $3.39 \%$ of children had severe anaemia $(\mathrm{Hb}<7 \mathrm{~g} / \mathrm{dL})$. The prevalence of anaemia (of any severity) ranged from $23.7 \%$ in Rwanda to $87.9 \%$ in Burkina Faso (see table 1).

\section{Bivariate analyses}

Bivariate analyses demonstrated a significant association between many potential predictor variables and level of anaemia (see tables 2 and 3). For tables 2 and 3, linear regression was used to show the association between each predictor on each level of the outcome (no anaemia, mild, moderate, severe anaemia). On average, children with

Table 1 Prevalence of anaemia in children age 6-59 months in countries included in analysis

\begin{tabular}{|c|c|c|c|c|}
\hline Country & Survey year & Children (n)* & $\begin{array}{l}\text { Proportion of children } \\
\text { with anaemia (\%) }\end{array}$ & $95 \% \mathrm{Cl}$ \\
\hline Benin & 2011-2012 & 3249 & 58.8 & (56.9 to 60.7 ) \\
\hline Burkina Faso & 2010 & 5998 & 87.9 & (86.9 to 88.8 ) \\
\hline Burundi & 2010 & 3164 & 34.0 & (32.1 to 35.9 ) \\
\hline Cameroon & 2011 & 4442 & 59.2 & (57.5 to 60.9) \\
\hline Congo Brazzaville & 2011-2012 & 3215 & 66.7 & (64.3 to 69.1) \\
\hline $\begin{array}{l}\text { Congo Democratic } \\
\text { Republic }\end{array}$ & 2013-2014 & 7085 & 57.5 & (55.8 to 59.2 ) \\
\hline Cote d'Ivoire & 2011-2012 & 2665 & 75.8 & (73.6 to 77.8 ) \\
\hline Ethiopia & 2011 & 8812 & 27.7 & (26.3 to 29.1 ) \\
\hline Gabon & 2012 & 2478 & 60.9 & (58.0 to 63.8 ) \\
\hline Gambia & 2013 & 2713 & 73.5 & (71.2 to 75.7 ) \\
\hline Ghana & 2014 & 2253 & 66.8 & (64.2 to 69.3 ) \\
\hline Guinea & 2012 & 2772 & 77.3 & (75.5 to 79.1 ) \\
\hline Lesotho & 2009-2010 & 1242 & 28.3 & ((25.5 to 31.2$)$ \\
\hline Malawi & 2010 & 4173 & 60.7 & (58.8 to 62.7) \\
\hline Mali & $2012-2013$ & 4207 & 81.9 & (80.5 to 83.2) \\
\hline Mozambique & 2011 & 4596 & 68.7 & (67.0 to 70.4 ) \\
\hline Namibia & 2013 & 1382 & 44.1 & (41.2 to 47.0 ) \\
\hline Niger & 2012 & 4541 & 73.7 & (72.1 to 75.3 ) \\
\hline Rwanda & 2010 & 3745 & 23.7 & (22.3 to 25.2 ) \\
\hline Sao Tome and Principe & 2008-2009 & 1405 & 63.7 & (60.6 to 66.6 ) \\
\hline Senegal & 2010-2011 & 3101 & 76.8 & (74.9 to 78.7 ) \\
\hline Sierra Leone & 2013 & 4161 & 79.9 & (78.4 to 81.4 ) \\
\hline Swaziland & 2006-2007 & 1768 & 40.9 & (38.4 to 43.4 ) \\
\hline Tanzania & 2009-2010 & 5912 & 53.6 & (52.0 to 55.1 ) \\
\hline Togo & 2013-2014 & 2716 & 70.9 & (69.0 to 72.7 ) \\
\hline Uganda & 2011 & 1786 & 43.2 & (40.4 to 46.2 ) \\
\hline Zimbabwe & 2010-2011 & 3223 & 52.9 & (51.0 to 54.8 ) \\
\hline Total & & 96804 & 59.9 & (59.5 to 60.3 ) \\
\hline
\end{tabular}

${ }^{*}$ Counts are weighted to reflect multistage survey sampling weights. 


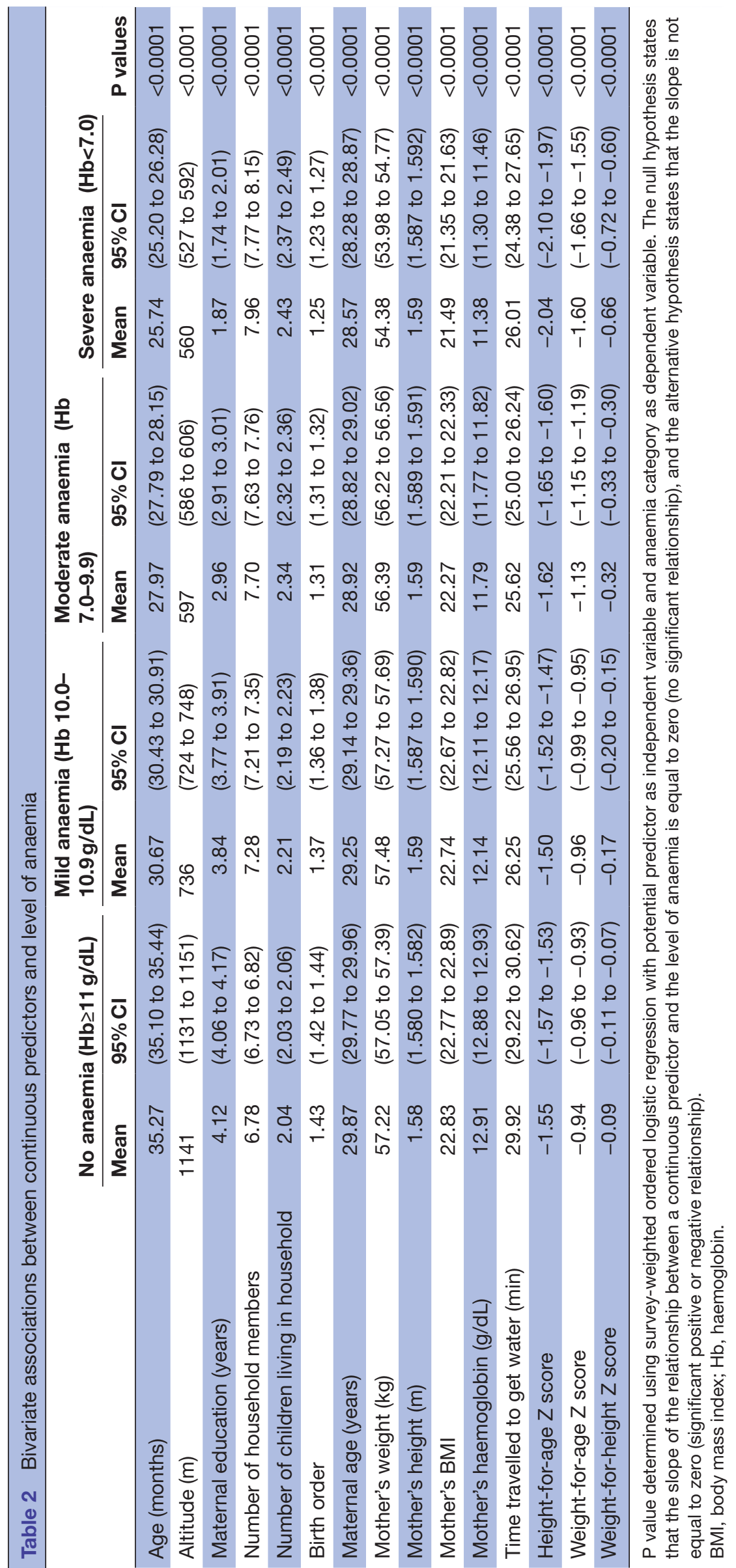




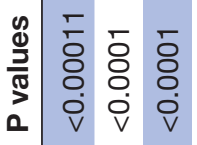

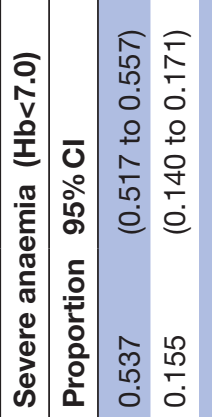

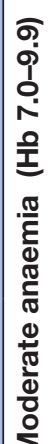

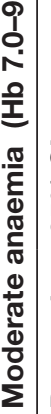

นึ

००

$\circ$ 인

U $\stackrel{2}{\stackrel{2}{\sim}}$

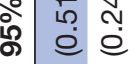

은

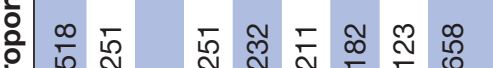

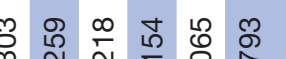
○ 0 O

ปิ

वे 0 ०

๘ ○ 0 O 0 O

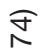

ํํㅇㄷㅐ

० 둥.

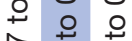

๑ 巳

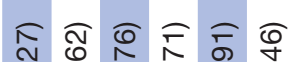

0.

웅ㅇㅇㅇㅛ

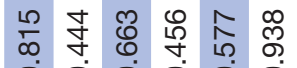

¿ ¿ 巳 e 巳

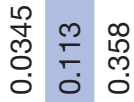

ㄷ.

0 0 o

흐

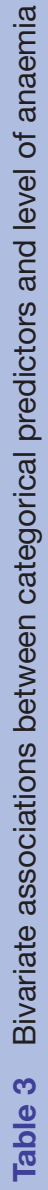

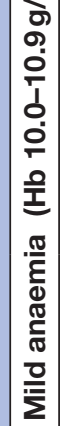

은 졷

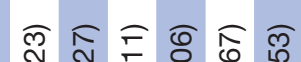

孚

色

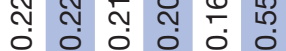

J $+\frac{0}{4}$

웅ㅇㅇㅇㅇ

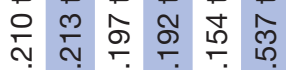

¿ 巳 巳 巳 巳

్ํ유 윰

०ं

웅요

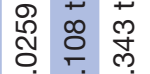

¿ อ 巳

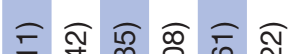

๙

$\begin{array}{llllll}0 & 0 & 0 & 0 & 0 & 0 \\ 0 & 0 & 0 & 0 & 0 & 0\end{array}$

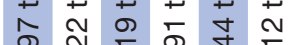

ร ส

¿ 0 อ 00

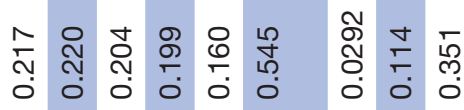

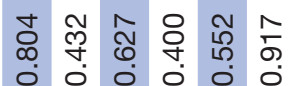

$\begin{array}{lll} & \\ 0 & 0 \\ 0 & 0 \\ 0 & 0 \\ 0 & 0\end{array}$

○ 00 O 0 O

ठิ

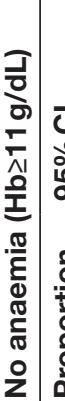

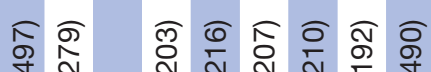

ণับ

$\circ 0$

$\begin{array}{llllll}0 & 0 & 0 & 0 & 0 & 0 \\ \circ & 0 & 0 & 0 & 0 & 0\end{array}$

M

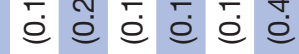

O

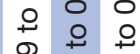

芒

¿ 巳

ฬ $\widehat{\mathcal{N}}$ \&

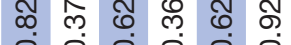

$\begin{array}{llllll}0 & 0 \\ 0 & 0 & 0 & 0 & 0 & 0 \\ 0 & 0 & 0 & 0 & 0\end{array}$

क

它

先

喜

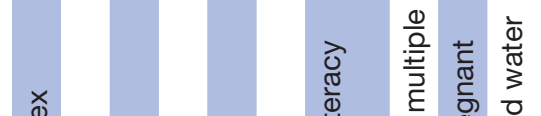

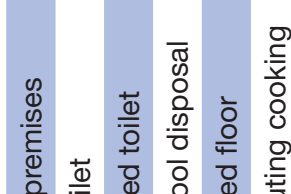

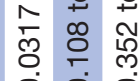

$\overline{8}$
8
0
v

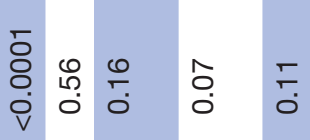

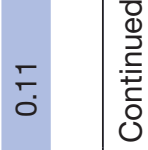

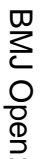

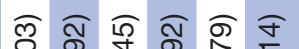

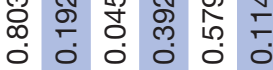

$\circ$ 웅 0 웅

다유

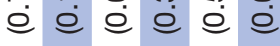

$\int 0$
0
0
0
0
0
0
0
0

ल

क人

o :

$\stackrel{\infty}{\infty}$

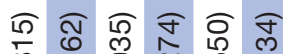

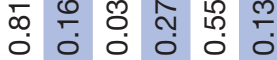

$\circ$ 웅ㅇㅇㅇ

员 กิ

¿ 巳 巳 e 巳 巳

ลิ

今.

ลิ

O.

กิ

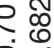

$\stackrel{\circ}{\grave{c}}$

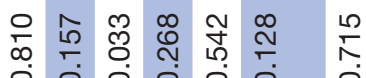

范

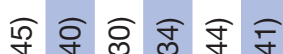

范

$\begin{array}{llllll}0 & 0 & 0 & 0 & 0 & 0 \\ 0 & 0 & 0 & 0 & 0 & 0\end{array}$

ల్ల

¿ 巳 巳 巳 巳 巳

竞

。

$+$

กิ

อ

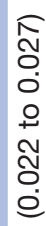

প్ల

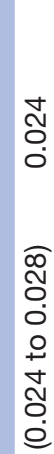

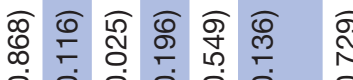

o 00 co

오 오 우 오 우

ర্ 주

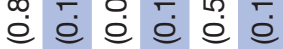



$\circ$

芩

อ

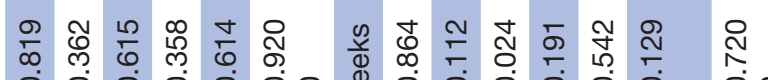

$\stackrel{\substack{0 \\ \hdashline}}{\circ}$

乡ं

OO

$\circ$

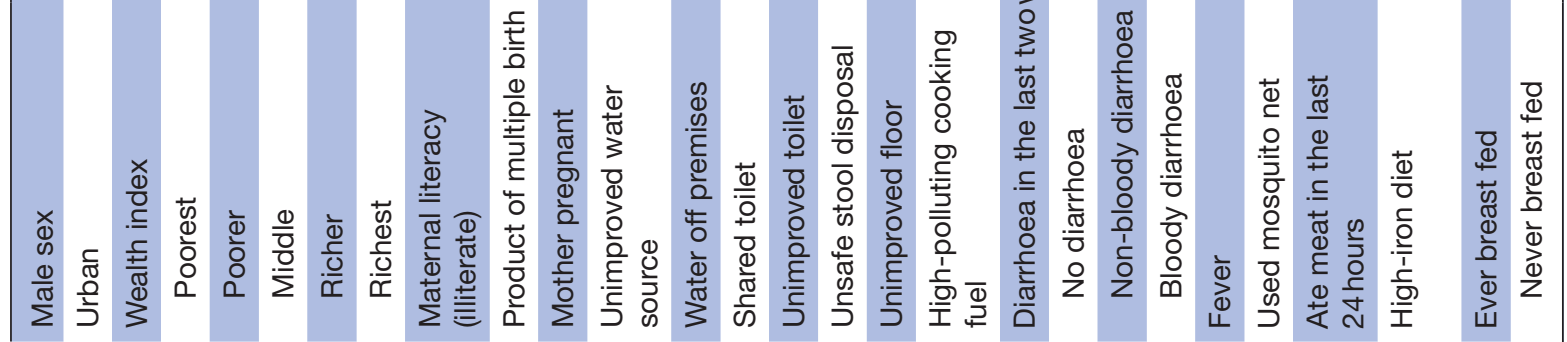

0
0
0
0
0
0
0
$\mathbb{1}$
0
$\mathbb{1}$
0
0
0
8
0
$\vdots$
0
0 


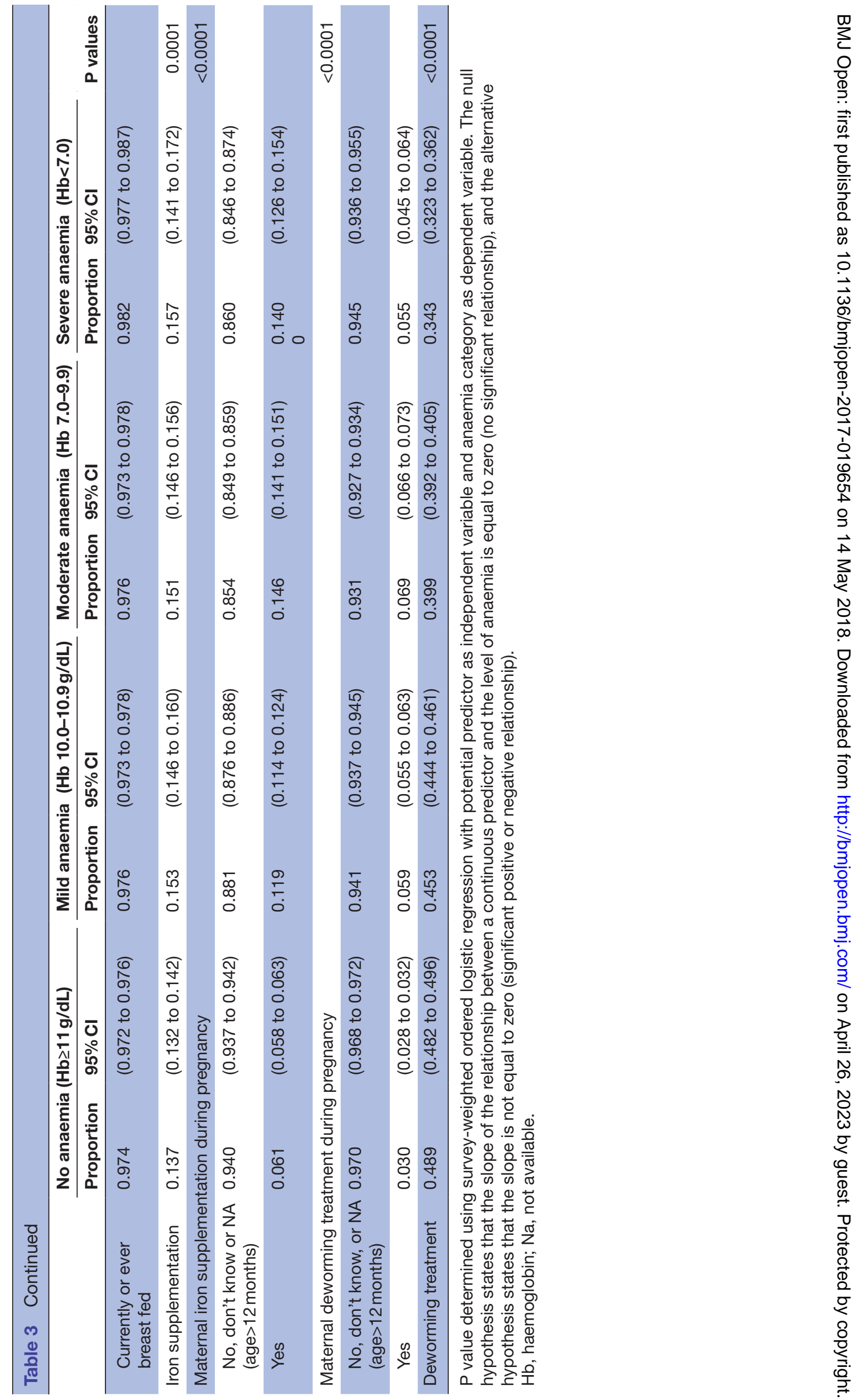


anaemia were younger, more likely to be male, living at lower altitude, using high-polluting cooking fuel, living in a low-income household, be living in a larger household, be the product of a multiple birth, have unimproved toilet facilities and have lower anthropometric indices (HAZ/ WAZ/WHZ). Children with anaemia were more likely to have a mother with the following characteristics: younger in age, less educated, lower BMI and lower Hb, taking iron supplementation and having undergone deworming during pregnancy. Children with anaemia were more likely to have recent diarrhoea or fever, be taking iron supplementation and not have undergone deworming treatment. There was no significant association between bednet usage, eating meat in the past 24 hours, having a high-iron diet and anaemia.

\section{Multivariable analyses and PAF}

Across all three multivariable linear regression models, eight variables were significantly positively associated with child $\mathrm{Hb}$ levels, including age of child (months), sex (female children on average had higher levels of $\mathrm{Hb}$ ), wealth, HAZ, mother's age, mother's BMI, current maternal pregnancy and mother's Hb. Additionally, two variables negatively predicted $\mathrm{Hb}$ levels, namely number of household members (more members in the household was associated with decreased $\mathrm{Hb}$ ) and presence of fever in the past two weeks. These results are shown in table 4. Several variables (maternal literacy, birth order, unimproved toilet, water source located off premises, maternal deworming treatment, non-bloody and bloody diarrhoea in the past two weeks) were only significant in the models with a larger sample size (model 1 or 2 ). Of the variables that were only present in a subset of the countries (model 2 or 3), altitude (positively associated with $\mathrm{Hb}$ ) and unsafe stool disposal (negatively associated with $\mathrm{Hb}$ ) were significant. Sensitivity analysis assigning either high or low values to HAZ did not result in a significant difference in the parameter estimates of the predictor variables (see online supplementary table A2.

In linear multivariable models 1 and 2 , we found a significant association between maternal deworming during pregnancy and higher child $\mathrm{Hb}$. Otherwise, findings from the logistic regression model were similar to the linear regression models, demonstrating significant associations between several risk factor groups and anaemia (see table 5). Maternal factors were associated with the greatest PAF (16.8\% (95\% CI $11.9 \%$ to $21.3 \%$ )), followed by socioeconomic factors (PAF $13.0 \%$ (95\% CI $10.9 \%$ to $15.6 \%)$ ).

\section{DISCUSSION}

In a large survey of 96804 children age 6-59 months across 27 SSA countries, we found a $59.9 \%$ prevalence of anaemia. Further, we found that many individual and household factors were associated with a child's risk for anaemia, especially maternal and socioeconomic factors. At a population level, these groups of variables are responsible for $67.8 \%$ of the burden of childhood anaemia.

When treating an individual child with anaemia, a paediatrician works to identify treatable causes, including micronutrient deficiencies and treatable infections (eg, malaria, intestinal parasites). Similarly, at a population level, reducing the prevalence of anaemia requires identifying and targeting the underlying upstream risk factors. ${ }^{34}$ In our analysis of DHS data, we found that demographic factors, environmental factors, socioeconomic factors, family structure, water/sanitation, nutrition and growth, maternal factors, recent illnesses and prophylactic measures all contributed to anaemia among young children in SSA. Notably, the individual effect size of several common public health interventions in our surveybednet usage, iron supplementation and deworming-is substantially smaller than the effect size associated with maternal and socioeconomic factors.

Our data indicate that child-level interventions may have some benefit in reducing the risk of anaemia, but not as much as measures focused on improving the health of the mother and the community. For example, we noted that across all models maternal pregnancy was associated with higher $\mathrm{Hb}$ levels in the child; this may reflect greater exposure to healthcare for the mother and indirectly better healthcare for the child or the effect of unmeasured confounding variables. In the linear multivariable models, we found that maternal BMI, maternal deworming and higher maternal $\mathrm{Hb}$ were associated with a higher child Hb. Similarly, reducing household crowding and improving sanitation (even more than clean water) were associated with higher child $\mathrm{Hb}$ levels.

Our findings are consistent with an analysis of 31815 mother-child pairs in the 25 SSA countries in the DHS by Wilunda et al, which found that children age 6-23 months whose mothers who took iron for at least 6 months prenatally or those who took both iron and deworming drugs prenatally had a lower risk of moderate/severe anaemia compared with those whose mothers did not take iron and deworming drugs. ${ }^{35}$ A 2015 systematic review for the US Preventive Services Task Force of iron supplementation in developed countries did not find any benefit to prenatal iron supplementation in infant haematological indices at 6 months,${ }^{36}$ though it is unclear how these findings apply to a low-income, middle-income country setting with high baseline prevalence of anaemia.

Translating the findings of this analysis into practice is feasible. Programmes targeting individual risk factors have been demonstrated to be successful, including iron supplementation, ${ }^{37-39}$ deworming ${ }^{40}$ and malaria control (including insecticide-treated bednets, antimalarial chemoprophylaxis and insecticide residual spraying). ${ }^{41}$ Implementation of an integrated programme that combines these individual interventions, however, has even greater potential. Siekmans et al reported on the effects of an integrated approach to reducing child vulnerability to anaemia in Ghana, Malawi and Tanzania. ${ }^{20}$ They found that a multifaceted intervention including 


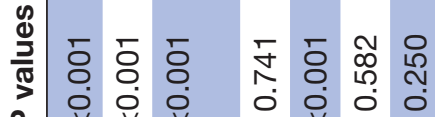

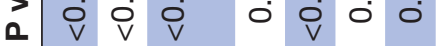

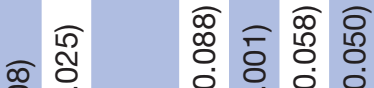

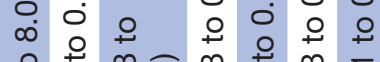

ত

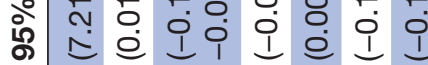

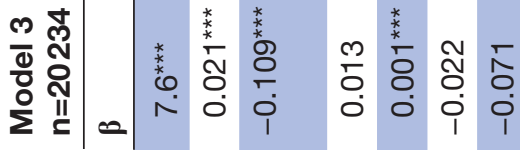

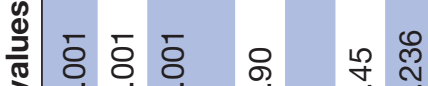

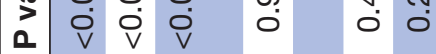

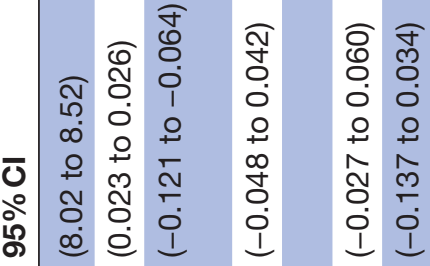

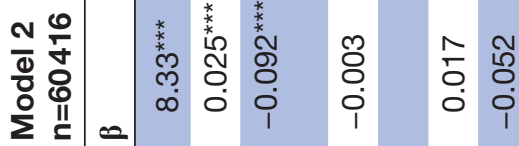

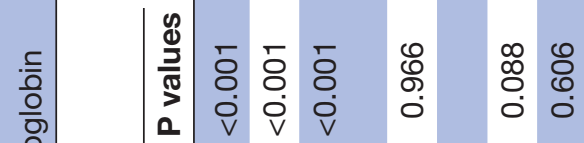

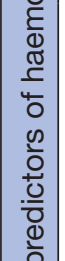

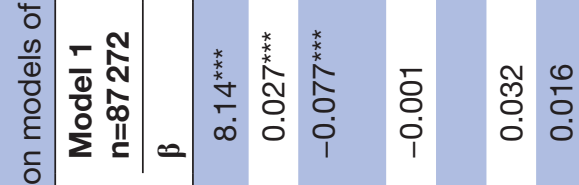

幽

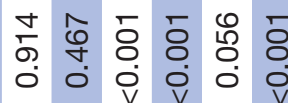

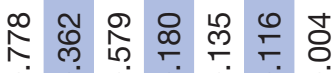

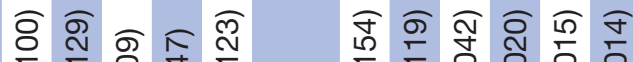

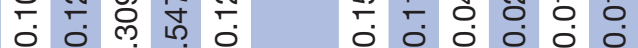

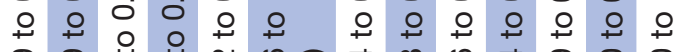

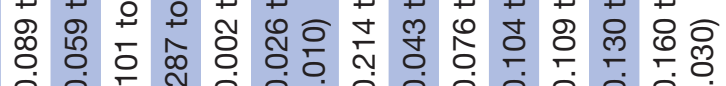

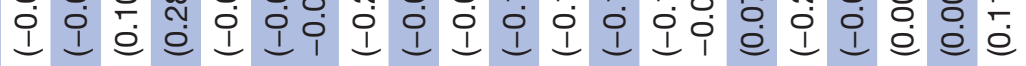

동

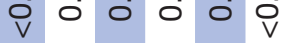

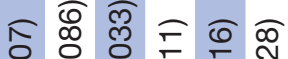

ᄃ.

웅

m ลิ

ㅇ.

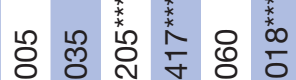

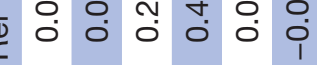

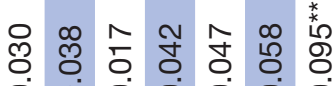

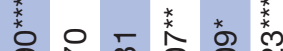

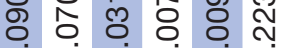

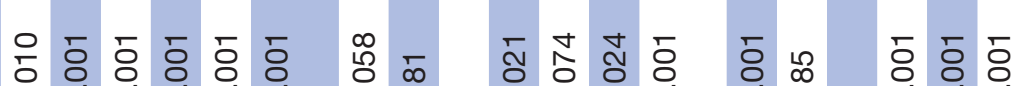

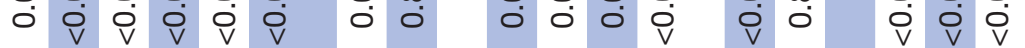

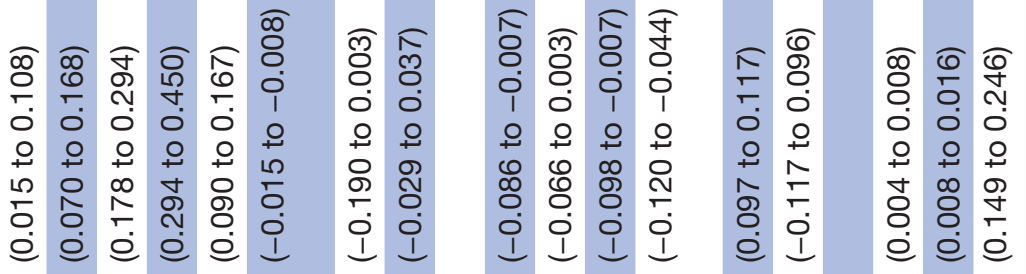

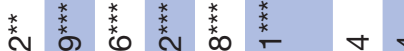
$\underset{\Phi}{\square}$

母.

굥

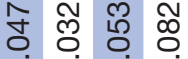

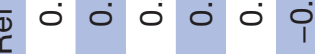

i

i 1 i 19

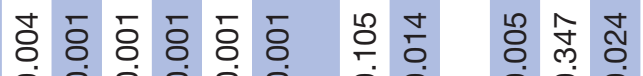

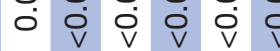

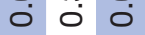

สิธูกิ

ภำ กิ

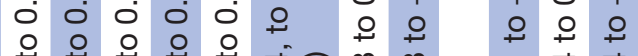

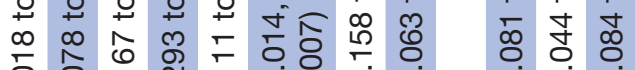

б โ

$\begin{array}{lll}1 & 1 & 1 \\ 0 & 1 & 0 \\ 0 & 1 & 0\end{array}$

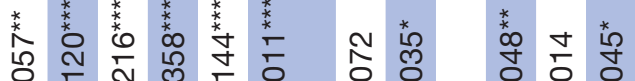

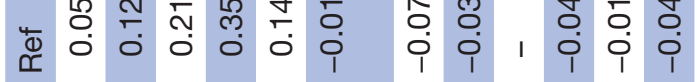

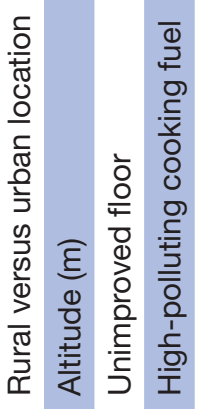

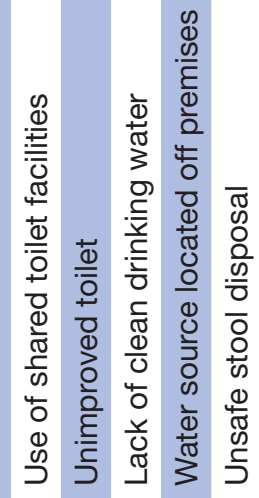

亘

○

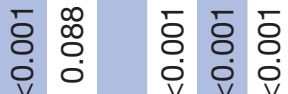

สิำ

ז.

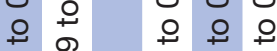

ᄂ

¿ 1 @

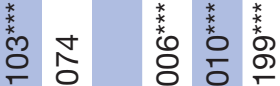

宁

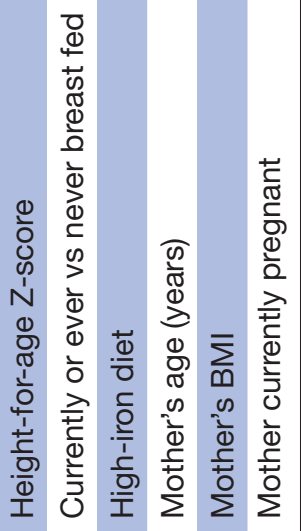




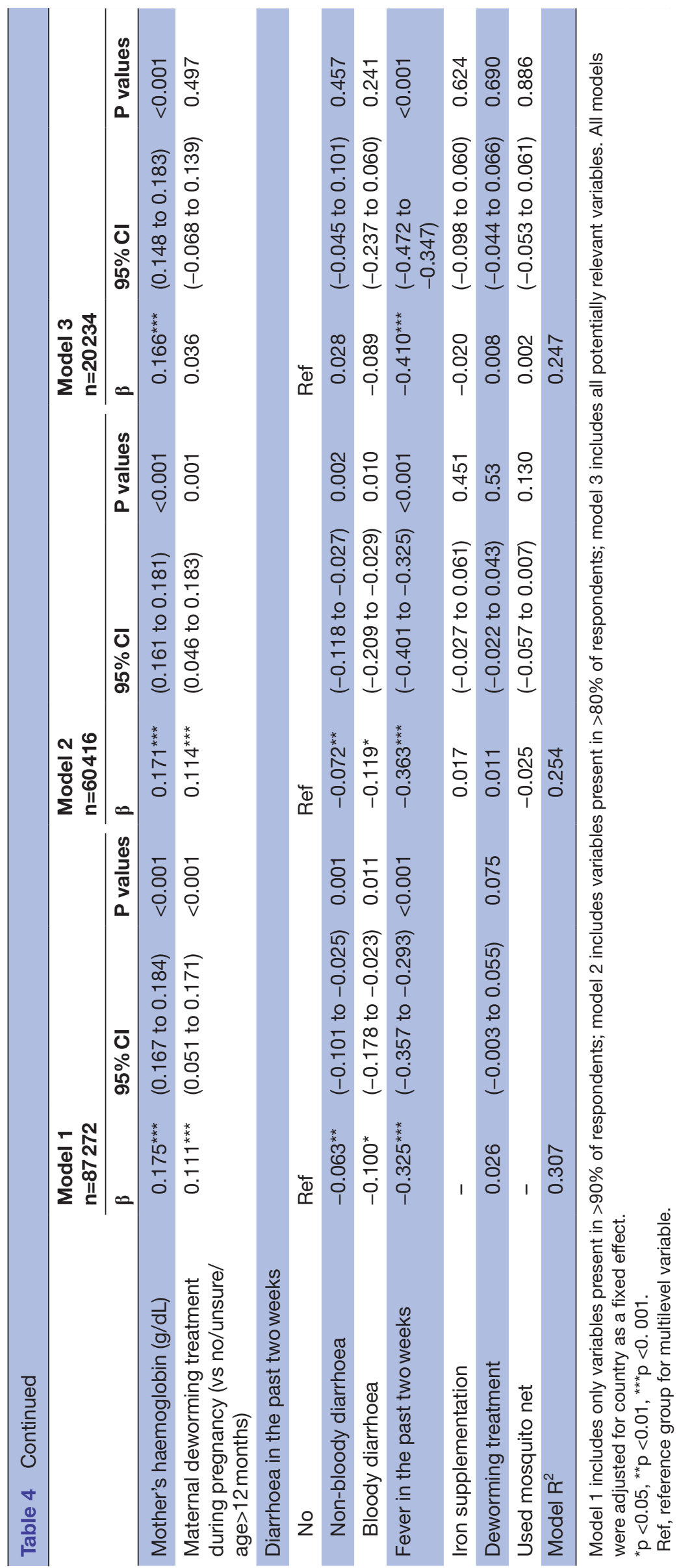

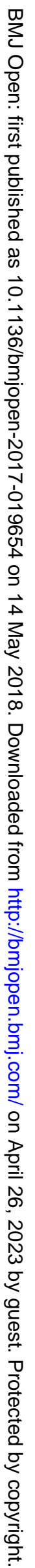


Table 5 Logistic regression model: risk factors for childhood anaemia (defined as haemoglobin $(\mathrm{Hb})<11 \mathrm{~g} / \mathrm{dL}$ ) and populationattributable fraction (PAF)

\begin{tabular}{|c|c|c|c|c|}
\hline Risk factor & OR & $95 \% \mathrm{Cl}$ & PAF (\%) & $95 \% \mathrm{Cl}$ \\
\hline Demographic & & & 11.3 & (10.5 to 12.2$)$ \\
\hline \multicolumn{5}{|l|}{ Age (months) } \\
\hline $6-11$ & $2.90^{\star \star \star}$ & (2.66 to 3.16 ) & & \\
\hline $12-23$ & $2.12^{\star \star \star}$ & (2.00 to 2.23 ) & & \\
\hline $23-59$ & - & & & \\
\hline Male sex & $1.12^{\star \star \star}$ & (1.08 to 1.17 ) & & \\
\hline Environmental & & & 1.3 & (0.3 to 2.3 ) \\
\hline Urban location & $1.06^{\star}$ & (1.00 to 1.13$)$ & & \\
\hline Improved floor & $1.06^{\star}$ & (1.00 to 1.13$)$ & & \\
\hline Clean cooking fuel & 0.99 & (0.90 to 1.10$)$ & & \\
\hline Socioeconomic & & & 13.0 & (10.7 to 15.3$)$ \\
\hline \multicolumn{5}{|l|}{ Wealth index } \\
\hline Poorest & $1.61^{\star \star \star}$ & (1.46 to 1.79$)$ & & \\
\hline Poorer & $1.48^{\star \star \star}$ & (1.35 to 1.63$)$ & & \\
\hline Middle & $1.40^{\star \star \star}$ & (1.28 to 1.52$)$ & & \\
\hline Richer & $1.25^{\star \star \star}$ & (1.16 to 1.35$)$ & & \\
\hline Richest & - & & & \\
\hline Maternal illiteracy & $1.19^{\star \star \star}$ & (1.13 to 1.25$)$ & & \\
\hline Family structure & & & 10.7 & (6.6 to 14.6$)$ \\
\hline \multicolumn{5}{|l|}{ Number of household members } \\
\hline $0-3$ & - & & & \\
\hline $4-6$ & 1.06 & (0.98 to 1.13 ) & & \\
\hline $7-9$ & $1.16^{\star \star \star}$ & (1.07 to 1.25$)$ & & \\
\hline $10-12$ & $1.20^{\star \star \star}$ & (1.10 to 1.32$)$ & & \\
\hline $12+$ & $1.28^{\star \star \star}$ & (1.16 to 1.42$)$ & & \\
\hline Product of multiple birth & 1.08 & (0.95 to 1.24$)$ & & \\
\hline \multicolumn{5}{|l|}{ Birth order } \\
\hline 1 & $1.29^{\star \star \star}$ & (1.16 to 1.43$)$ & & \\
\hline 2 & $1.20^{\star \star \star}$ & (1.08 to 1.33$)$ & & \\
\hline $3+$ & - & & & \\
\hline Water/sanitation & & & 4.0 & (2.1 to 5.9$)$ \\
\hline Unimproved toilet & 1.04 & (0.98 to 1.09 ) & & \\
\hline Lack of clean drinking water & 1.04 & (0.99 to 1.09 ) & & \\
\hline Water source located off premises & $1.12^{\star \star \star}$ & (1.05 to 1.19$)$ & & \\
\hline Nutrition and growth & & & 6.8 & (2.6 to 10.8$)$ \\
\hline Stunted & $1.32^{\star \star \star}$ & (1.27 to 1.38$)$ & & \\
\hline Currently or ever breast fed & 1.11 & (0.98 to 1.26$)$ & & \\
\hline Maternal factors & & & 16.8 & (11.9 to 21.4$)$ \\
\hline \multicolumn{5}{|l|}{ Mother's age (years) } \\
\hline$\leq 18$ & $1.30^{\star \star \star}$ & (1.13 to 1.48$)$ & & \\
\hline $19-24$ & $1.23^{\star \star \star}$ & (1.16 to 1.31$)$ & & \\
\hline $25-28$ & $1.13^{\star \star \star}$ & (1.07 to 1.20$)$ & & \\
\hline 29-34 & 1.06 & (1.00 to 1.12$)$ & & \\
\hline $35+$ & - & & & \\
\hline
\end{tabular}




\begin{tabular}{|c|c|c|c|c|}
\hline Risk factor & OR & $95 \% \mathrm{Cl}$ & PAF (\%) & $95 \% \mathrm{Cl}$ \\
\hline \multicolumn{5}{|l|}{ Mother's BMI } \\
\hline$<18.5$ & $1.20^{\star \star \star}$ & (1.10 to 1.30$)$ & & \\
\hline $18.5-24.9$ & $1.13^{\star \star *}$ & (1.07 to 1.19$)$ & & \\
\hline$>24.9$ & - & & & \\
\hline Mother not currently pregnant or unsure & 1.04 & (1.00 to 1.107$)$ & & \\
\hline Maternal anaemia & $1.85^{\star \star \star}$ & (1.76 to 1.95$)$ & & \\
\hline No anaemia & - & & & \\
\hline Mild anaemia $(\mathrm{Hb}<11 \mathrm{~g} / \mathrm{dL})$ & $1.64^{\star \star \star}$ & (1.55 to 1.73$)$ & & \\
\hline Moderate anaemia $(\mathrm{Hb}<10 \mathrm{~g} / \mathrm{dL})$ & $2.10^{\star \star *}$ & (1.98 to 2.22$)$ & & \\
\hline Severe anaemia $(\mathrm{Hb}<7 \mathrm{~g} / \mathrm{dL})$ & $2.35^{\star \star \star}$ & (1.95 to 2.83$)$ & & \\
\hline \multicolumn{5}{|l|}{ Maternal deworming during pregnancy } \\
\hline Yes & - & & & \\
\hline No, don't know or NA (age>12 months) & 1.05 & (0.93 to 1.18$)$ & & \\
\hline Age $>12$ months (NA) & - & & & \\
\hline Recent illnesses & & & 3.2 & (2.8 to 3.6$)$ \\
\hline \multicolumn{5}{|l|}{ Diarrhoea in the past two weeks } \\
\hline No & - & & & \\
\hline Non-bloody diarrhoea & $1.11^{\star \star}$ & (1.04 to 1.18$)$ & & \\
\hline Bloody diarrhoea & $1.21^{\star *}$ & (1.07 to 1.36$)$ & & \\
\hline Fever in the past two weeks & $1.42^{\star \star \star}$ & (1.35 to 1.49$)$ & & \\
\hline Prophylactic measures & & & 1.0 & (0.3 to 1.8$)$ \\
\hline No deworming treatment & $1.06^{\star \star}$ & (1.02 to 1.11$)$ & & \\
\hline Overall model PAF & & & 67.8 & (61.3 to 73.2$)$ \\
\hline
\end{tabular}

Model adjusted for country as fixed effect. No OR (-) listed for reference groups included in table.

${ }^{*} p<0.05,{ }^{* *} p<0.01,{ }^{* * *} p<0.001$.

BMI, body mass index; NA, not available.

nutrition education, breastfeeding promotion, dietary diversification, micronutrient supplementation, malaria and other parasitic disease control, water and sanitation promotion, and community and health facility level training and advocacy significantly reduced the effect of malaria on children's Hb. Similarly, a cluster randomised controlled trial in Burkina Faso demonstrated that an integrated agriculture, nutrition and behaviour change programme targeting mothers improved $\mathrm{Hb}$ among young infants. ${ }^{42}$

According to the most recent estimates from the United Nations Population Division, the under 5 population in SSA is 157.4 million, ${ }^{43}$ of which approximately 141.1 million are age 6-59 months (based on the age distribution in the DHS sample). Applying the observed anaemia prevalence of $59.9 \%$, about 85 million children age 6-59 months in SSA would be anaemic. Addressing maternal factors would have the potential to reduce anaemia in 16.8-30.2 million children; similarly, improving socioeconomic factors might prevent anaemia in 15.1-21.6million children. Although these numbers are an estimate, anaemia itself has a substantial social and economic cost, ${ }^{44}$ and reducing the prevalence of anaemia can help break the cycle of poverty in low-income countries.

While WHO recommends daily iron supplementation for all children 6 months and older living in areas where anaemia is highly prevalent, ${ }^{45}$ identification of risk factors might also direct more aggressive promotion of anaemia testing and prevention programmes to high-risk groups. For example, we found that children who are young, stunted and in the lowest socioeconomic group, and those with mothers who are illiterate, young, anaemic and underweight are at highest risk of anaemia. These children might benefit most from programmes focused on testing, deworming, iron supplementation and bednet promotion. Since the placenta is a rich source of blood and iron for the newborn at the time of delivery, it is important to emphasise the current WHO recommendations on delayed cord clamping of all deliveries. ${ }^{46-48}$ Interestingly, we also found that male children are at slightly higher risk of anaemia, perhaps related to X-linked diseases such as glucose- 6 phosphate dehydrogenase (not tested in this study).

Our findings must be interpreted in the context of the study's limitations. As a household survey, responses are 
subject to recall and misclassification bias. These data only capture events within the time window ascertained by the survey questions; for example, a history of iron supplementation (rather than recent supplementation in the past seven days) would not be captured in these data, a possible explanation for the apparent lack of association between iron supplementation and higher Hb. Anaemia testing was limited to $\mathrm{Hb}$; no further information on types of anaemia is available in these data. In addition, only a sample of living children were eligible to have their $\mathrm{Hb}$ measured, and children who died were sicker and more susceptible to both the risk factors for anaemia and its deleterious effects. Furthermore, DHS data on risk factors are limited to household and individual-level questions; the survey fails to capture school or community-level risk factors. To permit estimation of the effect of altitude on $\mathrm{Hb}$, our analyses used measured $\mathrm{Hb}$ values unadjusted for altitude. We would anticipate that use of altitude-adjusted $\mathrm{Hb}$ values as a threshold for defining anaemia would increase the estimated prevalence of anaemia. Finally, because DHS anaemia data are only available for 27 of the 48 SSA countries, this also limits the generalisability of the findings. ${ }^{49}$

A further limitation relates to the challenges in translating cross-sectional associations into conclusions on causation. Cross-sectional data make distinguishing cause from effect difficult; for example, anaemia may be both a cause and effect of stunting. As such, PAFs must be interpreted with caution. For some preventive measures (eg, bednet usage, iron supplementation), there may be confounding by indication. For example, families living in areas with high malaria rates may be more likely to use bednets, and this would to some extent mitigate the observed benefit of bednets. Similarly, there may be confounding by indication (eg, iron supplementation would be more common among children with anaemia). Many of the characteristics of poverty, including household crowding, poor water/sanitation, poor nutrition and access to medical care (including iron treatment), have complex interrelationships, ${ }^{49}$ and unpacking the causal relationships among these factors in causing or preventing anaemia requires further studies.

\section{CONCLUSION}

In summary, the findings from our analysis underscore the importance of family and socioeconomic context in childhood anaemia. Identifying risk factors for anaemia highlights potential targets for interventions, and these findings can guide policymakers wishing to reduce the prevalence of anaemia. In light of the multidimensional causes of anaemia, an integrated approach is needed to address childhood anaemia and its deleterious effects on neurocognitive development, response to infections and children's growth and well-being.

Contributors PPM conceptualised and designed the study, carried out the initial analyses, drafted the initial manuscript and approved the final manuscript as submitted. LA, OA and DH contributed to analysis of the data, revised the initial manuscript and approved the final manuscript as submitted. MOW, WD, JPK, DCC and PLH contributed to the study design and interpretation, critically reviewed and revised the initial manuscript, and approved the final manuscript as submitted.

Funding The Demographic and Health Surveys are funded by the United States Agency for International Development (USAID), as well as from participating countries and other donors. PPM has received funding from NIH grant F32 HL124951 and the Thrasher Research Fund to study the effects of anaemia on the outcomes of children with pneumonia. PLH has received funding from NIH grant 5K24AT003683. This work was conducted with support from Harvard Catalyst I The Harvard Clinical and Translational Science Center (National Center for Research Resources and the National Center for Advancing Translational Sciences, NIH Award UL1 TR001102) and financial contributions from Harvard University and its affiliated academic healthcare centers.

Disclaimer The content is solely the responsibility of the authors and does not necessarily represent the official views of Harvard Catalyst, Harvard University and its affiliated academic healthcare centers, or the National Institutes of Health.

Competing interests None declared.

Patient consent Not required.

Ethics approval General procedures and questionnaires for the DHS programme were reviewed and approved by the Informed Consent Form (ICF) International Institutional Review Board (IRB). Country-specific DHS protocols were additionally reviewed by the ICF IRB and by the IRB in each country. This analysis was reviewed and deemed exempt by the Partners Human Research Committee.

Provenance and peer review Not commissioned; externally peer reviewed.

Data sharing statement The DHS data are publicly available at https:// dhsprogram.com/.

Open Access This is an Open Access article distributed in accordance with the Creative Commons Attribution Non Commercial (CC BY-NC 4.0) license, which permits others to distribute, remix, adapt, build upon this work non-commercially, and license their derivative works on different terms, provided the original work is properly cited and the use is non-commercial. See: http://creativecommons.org/ licenses/by-nc/4.0/

(c) Article author(s) (or their employer(s) unless otherwise stated in the text of the article) 2018. All rights reserved. No commercial use is permitted unless otherwise expressly granted.

\section{REFERENCES}

1. Stevens GA, Finucane MM, De-Regil LM, et al. Global, regional, and national trends in haemoglobin concentration and prevalence of total and severe anaemia in children and pregnant and nonpregnant women for 1995-2011: a systematic analysis of populationrepresentative data. Lancet Glob Health 2013;1:e16-e25.

2. Kassebaum NJ, Jasrasaria R, Naghavi $M$, et al. A systematic analysis of global anemia burden from 1990 to 2010. Blood 2014;123:615-24.

3. Scott SP, Chen-Edinboro LP, Caulfield LE, et al. The impact of anemia on child mortality: an updated review. Nutrients 2014;6:5915-32.

4. Hurtado EK, Claussen AH, Scott KG. Early childhood anemia and mild or moderate mental retardation. Am J Clin Nutr 1999;69:115-9.

5. Ai Y, Zhao SR, Zhou G, et al. Hemoglobin status associated with performance IQ but not verbal IQ in Chinese preschool children. Pediatr Int 2012;54:669-75.

6. Greisen G. Mild anaemia in African school children: effect on running performance and an intervention trial. Acta Paediatr Scand 1986;75:662-7.

7. Adekanmbi AF, Ogunlesi TA, Olowu AO, et al. Current trends in the prevalence and aetiology of childhood congestive cardiac failure in Sagamu. J Trop Pediatr 2007;53:103-6.

8. Dhabangi A, Ainomugisha B, Cserti-Gazdewich C, et al. Cerebral Oximetry in Ugandan Children With Severe Anemia: Clinical Categories and Response to Transfusion. JAMA Pediatr 2016;170:995-1002.

9. MacCormick IJ, Beare NA, Taylor TE, et al. Cerebral malaria in children: using the retina to study the brain. Brain 2014;137(Pt 8):2119-42.

10. Ngesa O, Mwambi H. Prevalence and risk factors of anaemia among children aged between 6 months and 14 years in Kenya. PLoS One 2014;9:e113756. 
11. Reithinger R, Ngondi JM, Graves PM, et al. Risk factors for anemia in children under 6 years of age in Ethiopia: analysis of the data from the cross-sectional Malaria IndicatorSurvey, 2007. Trans $R$ Soc Trop Med Hyg 2013;107:769-76.

12. Semedo RM, Santos MM, Baião MR, et al. Prevalence of anaemia and associated factors among children below five years of age in Cape Verde, West Africa. J Health Popul Nutr 2014;32:646-57.

13. VanBuskirk KM, Ofosu A, Kennedy A, et al. Pediatric anemia in rural Ghana: a cross-sectional study of prevalence and risk factors. $J$ Trop Pediatr 2014;60:308-17.

14. Baranwal A, Baranwal A, Roy N. Association of household environment and prevalence of anemia among children under-5 in India. Front Public Health 2014;2:196.

15. Mamabolo RL, Alberts M. Prevalence of anaemia and its associated factors in African children at one and three years residing in the Capricorn District of Limpopo Province, South Africa. Curationis 2014;37:1-9.

16. Habte $\mathrm{D}$, Asrat $\mathrm{K}$, Magafu MG, et al. Maternal risk factors for childhood anaemia in Ethiopia. Afr J Reprod Health 2013;17:110-8.

17. Ayoya MA, Ngnie-Teta I, Séraphin MN, et al. Prevalence and Risk Factors of Anemia among Children 6-59 Months Old in Haiti. Anemia 2013;2013:502968-.

18. Khan JR, Awan N, Misu F. Determinants of anemia among 6-59 months aged children in Bangladesh: evidence from nationally representative data. BMC Pediatr 2016;16:3.

19. Magalhães RJ, Clements AC. Mapping the risk of anaemia in preschool-age children: the contribution of malnutrition, malaria, and helminth infections in West Africa. PLoS Med 2011;8:e1000438.

20. Siekmans K, Receveur O, Haddad S. Can an integrated approach reduce child vulnerability to anaemia? Evidence from three African countries. PLoS One 2014:9:e90108.

21. Soares Magalhães RJ, Langa A, Pedro JM, et al. Role of malnutrition and parasite infections in the spatial variation in children's anaemia risk in northern Angola. Geospat Health 2013;7:341-54.

22. Turyashemererwa FM, Kikafunda J, Annan R, et al. Dietary patterns, anthropometric status, prevalence and risk factors for anaemia among school children aged 5-11 years in Central Uganda. J Hum Nutr Diet 2013;26(Suppl 1):73-81.

23. Desai MR, Terlouw DJ, Kwena AM, et al. Factors associated with hemoglobin concentrations in pre-school children in Western Kenya: cross-sectional studies. Am J Trop Med Hyg 2005;72:47-59.

24. Nkulikiyinka R, Binagwaho A, Palmer K. The changing importance of key factors associated with anaemia in 6- to 59-month-old children in a sub-Saharan African setting where malaria is on the decline: analysis of the Rwanda Demographic and Health Survey 2010. Trop Med Int Health 2015;20:1722-32.

25. Alderman $\mathrm{H}$, Linnemayr S. Anemia in low-income countries is unlikely to be addressed by economic development without additional programs. Food Nutr Bull 2009;30:265-9.

26. Corsi DJ, Neuman M, Finlay JE, et al. Demographic and health surveys: a profile. Int J Epidemiol 2012;41:1602-13.

27. Short Fabic M, Choi Y, Bird S. A systematic review of Demographic and Health Surveys: data availability and utilization for research. Bull World Health Organ 2012;90:604-12.

28. Nkrumah B, Nguah SB, Sarpong N, et al. Hemoglobin estimation by the HemoCue ${ }^{\circledR}$ portable hemoglobin photometer in a resource poor setting. BMC Clin Pathol 2011;11:5.

29. International I. MEASURE DHS biomarker field manual. Calverton, Maryland, U.S.A: ICF International, 2012. https://dhsprogram.com/ pubs/pdf/DHSM7/DHS6_Biomarker_Manual_9Jan2012.pdf

30. World Health Organization. Haemoglobin concentrations for the diagnosis of anaemia and assessment of severity. Geneva: World Health Organization, 2011.

31. Rutstein SO, Johnson K. The DHS wealth index. Calverton, Maryland, USA: ORC Macro, 2004.
32. WHO/UNICEF Joint Water Supply and Sanitation Monitoring Programme WHO, UNICEF. Progress on drinking water and sanitation 2012. New York, N.Y., Geneva: UNICEF, World Health Organization, 2012.

33. Newson RB. Attributable and unattributable risks and fractions and other scenario comparisons. Stata J 2013;13:672-98.

34. Pasricha SR, Drakesmith $\mathrm{H}$, Black J, et al. Control of iron deficiency anemia in low- and middle-income countries. Blood 2013;121:2607-17.

35. Wilunda C, Tanaka S, Esamai F, et al. Prenatal anemia control and anemia in children aged 6-23 months in sub-Saharan Africa. Matern Child Nutr 2017;13:e12375.

36. Cantor AG, Bougatsos C, Dana T, et al. Routine iron supplementation and screening for iron deficiency anemia in pregnancy: a systematic review for the U.S. Preventive Services Task Force. Ann Intern Med 2015;162:566-76.

37. Gera T, Sachdev HP, Nestel P, et al. Effect of iron supplementation on haemoglobin response in children: systematic review of randomised controlled trials. J Pediatr Gastroenterol Nutr 2007;44:468-86.

38. Low M, Farrell A, Biggs BA, et al. Effects of daily iron supplementation in primary-school-aged children: systematic review and meta-analysis of randomized controlled trials. CMAJ 2013:185:E791-E802.

39. Pasricha SR, Hayes E, Kalumba K, et al. Effect of daily iron supplementation on health in children aged 4-23 months: a systematic review and meta-analysis of randomised controlled trials. Lancet Glob Health 2013;1:e77-e86.

40. Gulani A, Nagpal J, Osmond C, et al. Effect of administration of intestinal anthelmintic drugs on haemoglobin: systematic review of randomised controlled trials. BMJ 2007;334:1095.

41. Korenromp EL, Armstrong-Schellenberg JR, Williams BG, et al. Impact of malaria control on childhood anaemia in Africa -- a quantitative review. Trop Med Int Health 2004;9:1050-65.

42. Olney DK, Pedehombga A, Ruel MT, et al. A 2-year integrated agriculture and nutrition and health behavior change communication program targeted to women in Burkina Faso reduces anemia, wasting, and diarrhea in children 3-12.9 months of age at baseline: a cluster-randomized controlled trial. J Nutr 2015;145:1317-24.

43. UNDoEaSAP D. World Population Prospects: The 2015 Revision, DVD Edition. New York 2015.

44. Plessow R, Arora NK, Brunner B, et al. Social Costs of Iron Deficiency Anemia in 6-59-Month-Old Children in India. PLoS One 2015;10:e0136581.

45. World Health Organization. Nutrition for Health and Development, World Health Organization. Guideline. Daily iron supplementation in infants and children. Geneva: World Health Organization, 2016. http://apps.who.int/iris/bitstream/10665/204712/1/9789241549523_ eng.pdf?ua $=1 \& u a=1$

46. Gupta R, Ramji S. Effect of delayed cord clamping on iron stores in infants born to anemic mothers: a randomized controlled trial. Indian Pediatr 2002;39:130-5.

47. Hutton EK, Hassan ES. Late vs early clamping of the umbilical cord in full-term neonates: systematic review and meta-analysis of controlled trials. JAMA 2007;297:1241-52.

48. World Health Organization. Nutrition for Health and Development World Health Organization. Guideline. Delayed umbilical cord clamping for improved maternal and infant health and nutrition outcomes. Geneva, Switzerland: World Health Organization, 2014. http://apps.who.int/iris/bitstream/10665/148793/1/9789241508209_ eng.pdf

49. Schickedanz A, Dreyer BP, Halfon N. Childhood Poverty: Understanding and Preventing the Adverse Impacts of a MostPrevalent Risk to Pediatric Health and Well-Being. Pediatr Clin North Am 2015;62:1111-35. 